\title{
Role of Testosterone in the Treatment of Cardiovascular Disease
}

\author{
Carolyn M Webb and Peter Collins
}

Vascular Biology, National Heart and Lung Institute, Imperial College London and Department of Cardiology,

Royal Brompton and Harefield NHS Foundation Trust, London, UK

\begin{abstract}
Cardiovascular disease (CVD) is the most prevalent non-communicable cause of death worldwide. Testosterone is a sex hormone that is predominant in males but also occurs in lower concentrations in females. It has effects directly on the blood vessels of the cardiovascular system and on the heart, as well as effects on risk factors for CVD. Serum testosterone concentrations are known to decrease with age and reduced testosterone levels are linked to premature coronary artery disease, unfavourable effects on CVD risk factors and increased risk of cardiovascular mortality independent of age. A significant number of men with heart failure demonstrate reduced serum testosterone concentrations and there is early evidence suggesting that low testosterone levels affect cardiac repolarisation. Any association between endogenous testosterone concentrations and CVD in women has yet to be established. Testosterone replacement is used to treat men with hypogonadism but also has cardiovascular effects. This review will present the current evidence, expert opinion and controversies around the role of testosterone in the pathophysiology of CVD and surrounding the use of testosterone treatment and its effects on the cardiovascular system and CVD.
\end{abstract}

\section{Keywords}

Testosterone, men, cardiovascular disease, risk factors, treatment

Disclosure: The authors have no conflicts of interest to declare.

Received: 17 August 2017 Accepted: 29 September 2017 Citation: European Cardiology Review 2017;12(2):83-7. DOI: 10.15420/ecr.2017:21:1

Correspondence: Carolyn Webb, Department of Cardiology, Royal Brompton Hospital, Sydney Street, London SW3 6NP, UK. E: c.webb@imperial.ac.uk and

peter.collins@imperial.ac.uk

Cardiovascular disease (CVD) is the most prevalent non-communicable cause of death worldwide. ${ }^{1}$ The health and economic implications of caring for a growing ageing population with CVD is enormous. Maintaining a "healthy" elderly population that is mobile and independent with a good quality of life is vital. Testosterone is a sex hormone that is predominant in males, being secreted from the testes and adrenal glands, but it also occurs in lower concentrations in females, where it produced in the ovaries. In men, testosterone is primarily involved in sex differentiation and the development of secondary sex characteristics at puberty and it also contributes to spermatogenesis. It is involved in sex drive in both men and women.

Testosterone has effects directly on the blood vessels of the cardiovascular (CV) system and on the heart, as well as having effects on risk factors for CVD, see Figure 1.2 Serum testosterone concentrations are known to decrease with age. Epidemiological studies indicate that reduced testosterone levels are linked to premature coronary artery disease (CAD), ${ }^{3,4}$ unfavourable effects on CVD risk factors $^{5-7}$ and increased risk of CV mortality independent of age. ${ }^{8} \mathrm{~A}$ significant number of men with heart failure demonstrate reduced serum testosterone concentrations $s^{9,10}$ and there is early evidence suggesting that low testosterone levels affect cardiac repolarisation. ${ }^{2,11}$ A recent publication from the Atherosclerosis Risk in Communities observational study reported no association between endogenous testosterone and cerebrovascular disease. ${ }^{12}$ Any association between endogenous testosterone concentrations and CVD in women has yet to be established. The effects of endogenous testosterone on CVD have been well documented previously. ${ }^{13}$ Current interest has focussed more on the CV effects of exogenous testosterone, testosterone treatment and its effects on the CV pathophysiology. This has been driven by an increase in testosterone replacement use in men with "low" testosterone concentrations, even without other symptoms of hypogonadism, particularly in North America. ${ }^{14}$ In the following discussion we will present the current evidence and expert opinions on the $\mathrm{CV}$ effects of testosterone treatment, primarily in men as the evidence in women is currently less dependable.

\section{Testosterone and Treatment of CVD}

The purpose of testosterone replacement is to normalise low testosterone levels to improve symptoms. Clinically this is advised in patients with symptomatic hypogonadism supported by biochemical evidence; however, many of the studies presented in the following discussion have included men with low testosterone but not necessarily other signs of hypogonadism. Research interest has focussed mainly on the effects of testosterone treatment on the CV conditions of coronary atherosclerosis, myocardial ischaemia, heart failure and, more recently, in cardiac electrophysiology, see Figure 2.

\section{Metabolic Effects of Testosterone Treatment}

Endogenous testosterone concentrations are generally inversely related to CVD risk factors in men. Modifiable metabolic risk factors that are affected by testosterone concentrations include dyslipidaemia, central adiposity, insulin resistance and type 2 diabetes (T2DM). Epidemiological and observational studies largely show that low endogenous testosterone concentrations are independently associated with an atherogenic lipid profile, the metabolic syndrome and T2DM. ${ }^{15}$ 
Figure 1: Cardiovascular (CV) effects of Low Testosterone Levels in Men

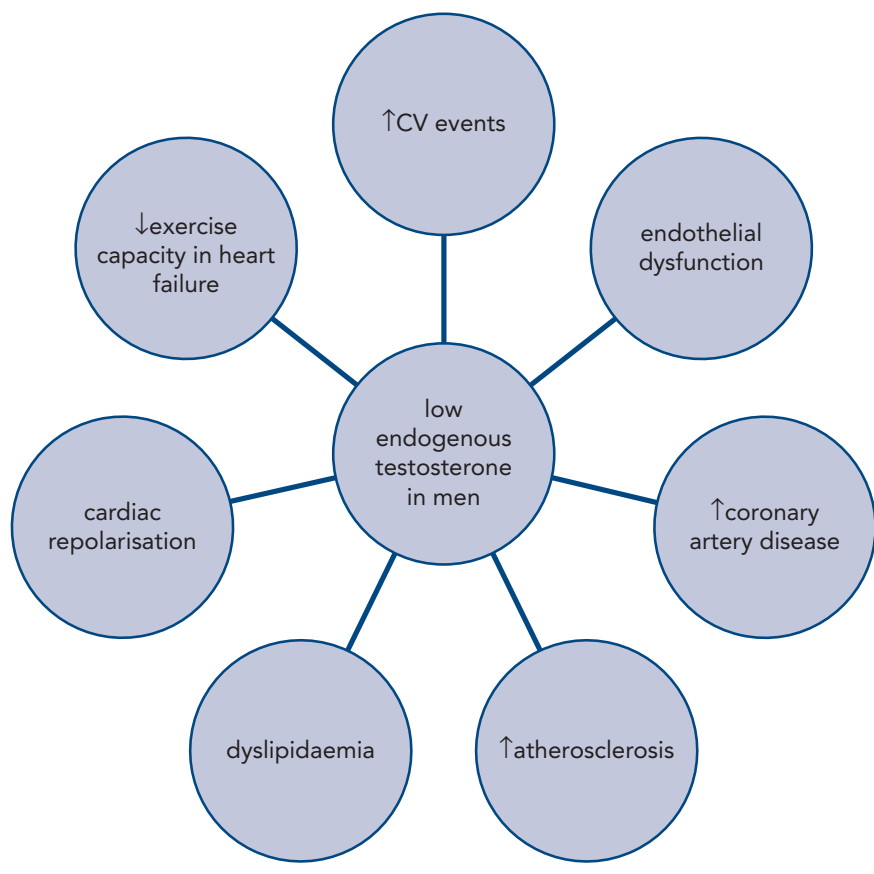

Figure 2: Cardiovascular (CV) Effects of Testosterone Treatment

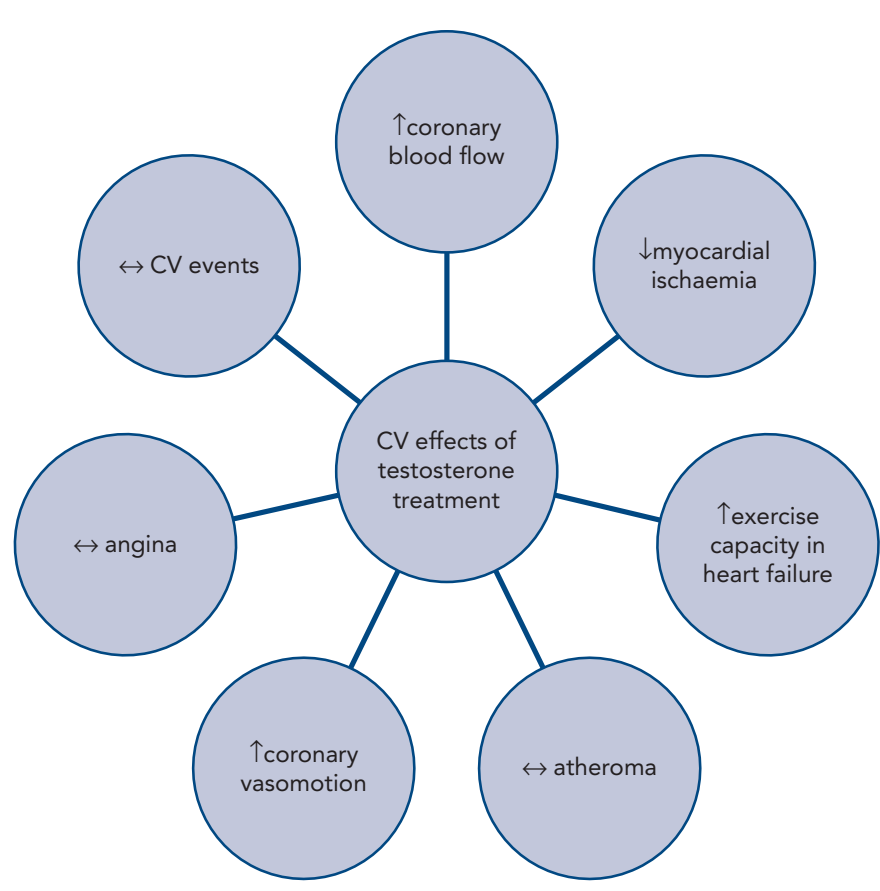

Lipid Profile

The evidence to date indicates that testosterone treatment reduces total and LDL-cholesterol concentrations. ${ }^{16-18}$ The evidence is less clear for HDL-cholesterol and may depend on the route of administration and resultant plasma concentrations of testosterone. ${ }^{15}$ Triglycerides are generally not changed by testosterone treatment. ${ }^{19}$ The Testosterone Replacement in Hypogonadal Men with Type 2 Diabetes and/or Metabolic Syndrome (TIMES2) study showed a reduction in lipoprotein(a) in hypogonadal men with and without T2DM or/and the metabolic syndrome treated with testosterone gel. ${ }^{16}$ In contrast, high doses of testosterone or anabolic steroids dramatically derange lipid profile. ${ }^{20}$

\section{Dysglycaemia and Diabetes}

The evidence consistently shows an association between low testosterone concentrations in men and insulin resistance, metabolic syndrome and T2DM. ${ }^{15}$ A number of interventional studies show an improvement in insulin resistance and glycaemic control in men with T2DM taking testosterone treatment. 16,21,22 In the European TIMES2 study, testosterone gel reduced measures of insulin resistance by up $16 \%$ after 1 year in men with the metabolic syndrome with or without T2DM. ${ }^{16}$ The BLAST study reported a decrease in $\mathrm{HbA}_{1 \mathrm{c}}$ levels in men with diabetes assigned to testosterone undecanoate for 24 weeks, with a greater effect seen in men with poorly-controlled T2DM. ${ }^{23}$

\section{Testosterone Treatment and Atherosclerosis}

Observational studies indicate that low testosterone concentrations have a detrimental effect on atherosclerosis. For example, testosterone concentrations are negatively associated with carotid artery intimamedia thickness, a measure of atheroma burden. ${ }^{24}$ The long-term consequences of testosterone supplementation on atherosclerosis in older men have been the focus of a number of recent studies. The Testosterone's Effects on Atherosclerosis Progression in Aging Men (TEAAM) trial was designed to determine the effect of increasing circulating testosterone concentrations into a range that is midnormal for young men on subclinical atherosclerosis progression in older men with low or low-normal testosterone levels, but not necessarily with symptoms of hypogonadism. ${ }^{25}$ The TEAAM trial enrolled just over 300 men in a randomised, placebo-controlled study of testosterone gel. This trial failed to show any benefit of testosterone compared with placebo on carotid intima-media thickness and coronary calcium, which were the co-primary endpoints, nor on the secondary outcomes of sexual function or quality of life. The authors commented that the results may have been influenced by concomitant medications such as statins and that the results of measures of sexual function may differ in men with symptomatic hypogonadism. Following on from TEAAM, the Cardiovascular Trial, one of the seven placebo-controlled Testosterone Trials, ${ }^{26}$ investigated the effects on coronary atherosclerosis of 1 year of testosterone gel treatment in 138 older, symptomatic, hypogonadal men, assessed by coronary computed tomographic angiography. ${ }^{27}$ Up to $50 \%$ of this study population had CAD or risk factors for CAD. ${ }^{27}$ Compared with placebo, testosterone treatment was associated with a significantly greater increase in coronary artery non-calcified plaque volume and total plaque volume. Similar to the TEAAM trial, there was no significant effect on coronary calcium score. An increase in atheroma burden does not necessarily translate into an increased rate of $\mathrm{CV}$ events, and neither study was powered to draw conclusions on this. These studies provide evidence for caution in the use of testosterone treatment. Larger studies are needed to understand the clinical implications of these findings.

\section{Coronary Blood Flow, Myocardial Ischaemia and} Angina in Men with CAD

Testosterone has directeffects on arteries independent of the reproductive system. Evidence for this has come from both basic scientific ${ }^{28-30}$ and clinical studies. ${ }^{31-36}$ Clinical studies show the favourable effects of shortor longer-term exposure to testosterone treatment on coronary and peripheral vasomotion and peripheral arterial stiffness. ${ }^{31-36}$ Physiological concentrations of intracoronary testosterone cause epicardial coronary artery dilatation and increases in volume blood flow in men with CAD. ${ }^{31}$ To investigate the effects of longer-term testosterone treatment on coronary blood flow, cardiac magnetic resonance myocardial perfusion 
scans were performed in men with CAD before and 8 weeks following oral testosterone treatment in a placebo-controlled, cross-over study. ${ }^{32}$ Myocardial perfusion was enhanced in myocardium supplied by unobstructed coronary arteries but not in areas supplied by coronary arteries with significant atherosclerosis, concurring with previous findings. ${ }^{31,32}$ The lack of effect of testosterone on myocardium supplied by significantly diseased coronary arteries may explain the results of studies of oral, transdermal and intramuscular testosterone treatment that failed to demonstrate an improvement in the frequency of anginal symptoms of men with CAD. ${ }^{32,37,38}$ However, these results do not explain the favourable effects of short- and longer-term testosterone treatment on signs of myocardial ischaemia in men with chronic stable angina. ${ }^{37,39,40}$ The number of studies that have investigated this is small, each enrolling a relatively small number of patients and using varying preparations of testosterone. The conclusions that can be drawn from these data and used to direct clinical practice are therefore limited. The largest study to date included 46 men with stable angina and baseline testosterone concentrations at the lower end of the normal range who were treated with a transdermal testosterone patch or placebo for 12 weeks in a parallel designed study. ${ }^{37}$ Time to exerciseinduced myocardial ischaemia was prolonged by testosterone treatment compared with placebo, with the effect being more pronounced in men with lower baseline testosterone concentrations. ${ }^{37}$ The study of longest duration thus far is a 12-month parallel, placebo-controlled trial using a testosterone undecanoate injection administered four times per year. ${ }^{40}$ Thirteen men with angina, signs of myocardial ischaemia on treadmill exercise testing and plasma testosterone concentrations $<12 \mathrm{nmol} / \mathrm{l}$ completed the study, with the results showing a significant delay in time to myocardial ischaemia in men taking testosterone versus placebo. ${ }^{40}$ Larger studies are needed to clarify any clinical application of testosterone treatment in men with myocardial ischaemia, anginal symptoms and low testosterone concentrations.

\section{Testosterone and Heart Failure}

Testosterone deficiency is estimated to affect approximately a third of men with chronic heart failure. Low circulating levels of testosterone independently correlate with exercise intolerance in men with heart failure ${ }^{41}$ and relate to the muscle-wasting characteristic of the condition. ${ }^{42}$ The excess of catabolic hormones and a relative deficiency of anabolic hormones in heart failure have been well documented, ${ }^{42,43}$ and in the past decade testosterone has been investigated as a potential therapy to correct the anabolic balance.

The first study was a small randomised, double-blind, placebocontrolled, cross-over trial that included men with chronic heart failure. ${ }^{44}$ Compared with placebo, a single dose of buccal testosterone increased cardiac output and reduced systemic vascular resistance, with the maximal effect coinciding with maximal free testosterone concentrations at 180 minutes. ${ }^{44}$ Since then, the same group and others have shown the beneficial effects of a variety of testosterone preparations on exercise capacity, oxygen consumption and functional class, with treatment periods lasting from 12 weeks to 12 months. ${ }^{45-47}$

There has been one study of testosterone treatment undertaken in elderly women with heart failure. ${ }^{48}$ Given via a transdermal patch for 6 months, testosterone significantly increased the distance walked in a 6-minute walk test and improved peak oxygen consumption, despite the women having pre-treatment testosterone concentrations in the normal range. ${ }^{48}$ The authors speculated that a peripheral mechanism of action might explain this effect.
A meta-analysis published in 2012 reinforced the beneficial effect of testosterone treatment on exercise capacity and oxygen consumption in patients with heart failure. ${ }^{49}$ However, reports of the effects of testosterone treatment on muscle strength in men with heart failure are not consistent, with some showing a null effect ${ }^{45}$ and others finding a benefit. ${ }^{46}$ This may be because none of these studies included patients with cachexia or muscle wasting. Apart from the testosterone patch, ${ }^{45}$ generally testosterone was well tolerated in heart failure studies to date. However, on average these studies only lasted a few months and the numbers included were small. Future studies with a longer duration of treatment, a larger study population and including patients with muscle wasting should produce valuable evidence with which to guide clinical practice.

\section{Testosterone and Cardiovascular Events}

Controversy surrounds the conflicting evidence on the effects of testosterone on CV events. Prospective population studies, such as the Health in Men Study, found that low testosterone concentrations were associated with an increased risk of incident stroke, but other studies reported no association between testosterone levels and CV events. ${ }^{50-53}$ Data from a more recent study in Sweden show an inverse association between both serum testosterone and sex hormone binding globulin concentrations and the risk of $\mathrm{CV}$ events, with high testosterone ( $\geq 550 \mathrm{ng} / \mathrm{dl}$ ) predicting reduced fatal and nonfatal CV events. ${ }^{54}$

Whether testosterone treatment has a favourable effect on CV events in men is a contentious issue. Two large observational studies reported an increased risk of adverse outcomes (death, myocardial infarction and stroke) in testosterone-treated men, particularly in men aged $>75$ years. 55,56 However, the results of these studies have been criticised and must be considered in view of the fact that there was no check of testosterone levels or drug compliance following testosterone initiation.9.57 Contrary to these studies, others have shown a decreased risk of CV events and mortality in testosterone users versus non-users. ${ }^{58,59}$ An interesting approach was used in an observational study that grouped a large cohort of men with low testosterone concentrations, newly treated with testosterone and then followed for 6 years, into those that achieved a normalised testosterone concentration and those that did not. ${ }^{60}$ Compared with those not achieving normal testosterone concentrations and with never-users of testosterone treatment, men achieving normalised testosterone concentrations had a lower relative risk of all-cause mortality, myocardial infarction and stroke. ${ }^{60}$ The discrepancies in the findings of these observational studies may be explained by differences in the age of the study cohorts, co-existing disease (Vigen et al. included men referred for coronary angiography ${ }^{46}$ the population studied by Sharma et al. was healthy with no known $C V D^{50}$ ) and knowledge of compliance with testosterone therapy after initiation. ${ }^{56,60}$

Randomised controlled trials of testosterone treatment in men with low testosterone levels also report conflicting results. The Testosterone Treatment in Older Men with Mobility Limitations (TOM) trial of men aged $\geq 65$ years was stopped early due to CV events in the testosteronetreated group; 61 however, the study was not designed to report on safety and whether the events were hard endpoints has been a subject of contention. ${ }^{9}$ Other randomised trials have been too small to draw conclusions about the risks of testosterone treatment, although the reported adverse event rates were similar in the testosteronetreated group versus placebo. ${ }^{25,27,62}$ There are obvious parallels with hormone-replacement treatment in women in past decades, where 
observational studies indicated a benefit of postmenopausal hormone therapy on CVD risk but the results of randomised trials did not support this. Unequivocal trials of testosterone treatment in a clinically-relevant population are needed to inform users and prescribers of the safety of testosterone treatment; however, we must acknowledge that this would be an enormous undertaking. ${ }^{63}$

\section{Risks of Testosterone Treatment}

Testosterone administration in hypogonadal men can cause sideeffects such as erythrocytosis (more so with oral preparations), fluid retention, benign prostatic hyperplasia, hepatotoxic and neoplastic effects (mostly with oral preparations but not testosterone undecanoate), gynaecomastia and acne and skin reactions (mostly with patches). ${ }^{64}$ Increased haematocrit and haemoglobin levels and small detrimental effects on lipids have also been documented. There is much controversy over the association of testosterone treatment with an increased incidence of prostate cancer, which is discussed in detail elsewhere. ${ }^{64,65}$ In brief, there is no evidence for an increased risk of prostate-cancer-specific death related to testosterone treatment in either direction; however, there is evidence implying that testosterone treatment may adversely affect the progression of prostate cancer. ${ }^{66}$ Large-scale, long-term trials are needed to clarify the safety of testosterone treatment. The current recommendation from the Endocrine Society is to make "a careful diagnosis of androgen deficiency only in men with consistent symptoms and signs and unequivocally low serum testosterone levels", then to treat men with confirmed symptomatic androgen deficiency with testosterone therapy. ${ }^{67}$ Once testosterone treatment is initiated, it is suggested that mid-normal range testosterone levels are aimed for and that therapy is monitored using a standardised plan. ${ }^{67}$

\section{Conclusions}

Low endogenous testosterone concentrations can affect risk factors for CVD, atheroma development and vasomotion beyond the blood vessels of the reproductive system. They are associated with coronary atherosclerosis and heart failure in approximately a third of men. The discrepant results of clinical studies of testosterone replacement in older men with hypogonadism have resulted in controversy over its clinical use, largely concerning variances in CV event rate and the ability of these studies to generate reliable data on this endpoint. Testosterone treatment is not without sideeffects and risks. The Endocrine Society 2010 clinical practice guideline and the European Menopause and Andropause Society give detailed recommendations on the use of testosterone therapy in men with androgen deficiency, supporting such treatment in men with symptomatic androgen deficiency (repeated early morning low serum testosterone levels) followed by scheduled testing for efficacy and adverse events. 67,68 Testosterone treatment is not recommended in men with breast or prostate cancer, suspected or increased risk of prostate cancer, haematocrit $>50 \%$ or uncontrolled heart failure. ${ }^{67,68}$ Individualised management of patients is recommended, including the evaluation of comorbidities and careful risk-benefit assessment, and not general prescription of testosterone therapy to all ageing men with low testosterone. ${ }^{67,68}$ A number of professional organisations agree that there is no consistent evidence that testosterone treatment either increases or decreases CV risk..$^{68}$ Large studies with hard CV endpoints in older symptomatic hypogonadal men are needed encompassing longer-term treatment periods and investigating the differing types of testosterone replacement available in order to provide strong evidence on which to base clinical decisions in this population.
1. World Health Organization. World Health Statistics 2009. 2009 Available at: http://www.who.int/whosis/whostat/2009/en/ (accessed 25 October 2016)

2. Oskui PM, French WJ, Herring MJ, et al. Testosterone and the cardiovascular system: a comprehensive review of the clinica literature. J Am Heart Assoc 2013;2:e000272. DOI: 10.1161/ JAHA.113.000272; PMID: 24242682

3. Corona G, Rastrelli G, Monami M, et al. Hypogonadism as a risk factor for cardiovascular mortality in men: a meta-

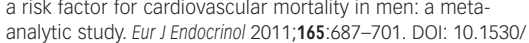
analytic study. Eur J Endocrino/

4. Ruige JB, Mahmoud AM, De BD, Kaufman JM. Endogenous testosterone and cardiovascular disease in healthy men: a meta-analysis. Heart 2011;97:870-5. DOI: 10.1136/ hrt.2010.210757; PMID: 21177660.

5. Haffner SM, Mykkanen L, Valdez RA, Katz MS. Relationship of sex hormones to lipids and lipoproteins in nondiabetic men. J Clin Endocrinol Metab 1993;77:1610-5. DOI: 10.1210/ jcem.77.6.8263149; PMID: 8263149.

6. Simon D, Charles MA, Nahoul K, et al. Association between plasma total testosterone and cardiovascular risk factors in healthy adult men: The Telecom Study. I Clin Endocrinol Metab 1997;82:682-5. DOI: 10.1210/jcem.82.2.3766; PMID: 9024276.

7. Zmuda JM, Cauley JA, Kriska A, et al. Longitudinal relation between endogenous testosterone and cardiovascular disease risk factors in middle-aged men. A 13-year follow-up
of former multiple risk factor intervention trial participants. Am J Epidemiol 1997;146:609-17. DOl: 10.1093/oxfordjournals. aje.a009326; PMID: 9345114

8. Khaw KT, Dowsett M, Folkerd E, et al. Endogenous testosterone and mortality due to all causes, cardiovascular disease, and cancer in men: European prospective investigation into cancer in Norfolk (EPIC-Norfolk) Prospective Population Study. Circulation 2007;116:2694-701. DOI: 10.1161/ CIRCULATIONAHA. 107.719005; PMID: 18040028

9. Kloner RA, Carson C, III, Dobs A, et al. Testosterone and cardiovascular disease. I Am Coll Cardiol 2016;67:545-57. DOl: 10.1016/j.jacc.2015.12.005; PMID: 26846952.

10. Jankowska EA, Biel B, Majda J, et al. Anabolic deficiency in men with chronic heart failure: prevalence and detrimental men with chronic heart failure: prevalence and detrimental
impact on survival. Circulation 2006;114:1829-37. DOI: 10.1161 Impact on survival. Circulation 2006,114.1829-37.

11. Zhang Y, Ouyang P, Post WS, et al. Sex-steroid hormones and electrocardiographic QT-interval duration: findings from the third National Health and Nutrition Examination Survey and the Multi-Ethnic Study of Atherosclerosis. Am J Epidemio
2011:174:403-11. DOI: 10.1093/aje/kwr172: PMID: 21768401 12. Srinath R, Gottesman RF, Hill GS, et al. Association between endogenous testosterone and cerebrovascular disease in the ARIC study (Atherosclerosis Risk in Communities). Stroke 2016;47:2682-8. DOI: 10.1161/STROKEAHA.116.014088; PMID: 27729576.

13. Webb CM, Collins P. Testosterone and coronary artery disease in men. Maturitas 2010;67:15-9. DOI: 10.1016/ j.maturitas.2010.03.029; PMID: 20447781.

14. Handelsman DJ. Global trends in testosterone prescribing 2000-2011: expanding the spectrum of prescription drug misuse. Med J Aust 2013;199:548-51. DOI: 10.5694/mja13.10111; PMID: 24138381

15. Rao PM, Kelly DM, Jones TH. Testosterone and insulin resistance in the metabolic syndrome and T2DM in men. Nat Rev Endocrinol 2013;9:479-93. DOI: 10.1038/nrendo.2013. 122; PMID: 23797822

16. Jones TH, Arver S, Behre HM, et al. Testosterone replacemen in hypogonadal men with type 2 diabetes and/or metabolic syndrome (the TIMES2 study). Diabetes Care 2011;34:828-37. syndrome (the TIMES2 study). Diabetes Care

17. Permpongkosol S, Tantirangsee N, Ratana-olarn K. Treatment of 161 men with symptomatic late onset hypogonadism with long-acting parenteral testosterone undecanoate: effects on body composition, lipids, and psychosexual complaints. I Sex Med 2010;7:3765-74. DOI: 10.1111/j.1743-6109.2010.01994.x PMID: 20807330.

18. Kalinchenko SY, Tishova YA, Mskhalaya GJ, et al. Effects of testosterone supplementation on markers of the metabolic syndrome and inflammation in hypogonadal men with the metabolic syndrome: the double-blinded placebo-controlled metabolic syndrome: the double-blinded placebo-contr:
Moscow study. Clin Endocrinol (Oxf) 2010;73: 602-12. DOl: Moscow study. Clin Endocrinol (OXf) 2010;73: 602-12. DOF:
10.1111/i.1365-2265.2010.03845.x; PMID: 20718771. 10.1111/j.1365-2265.2010.03845.X; PMID: 20718771.
Agledahl I, Hansen JB, Svartberg J. Impact of testosterone treatment on postprandial triglyceride metabolism in elderly men with subnormal testosterone levels. Scand I Clin Lab Invest 2008;68:641-8. DOI: 10.1080/00365510801999068; PMID: 19378437

20. Hartgens $F$, Kuipers H. Effects of androgenic-anabolic steroids in athletes. Sports Med 2004;34:513-54. DOI: 10.2165/00007256200434080-00003: PMID: 15248788.

21. Kapoor D, Goodwin E, Channer KS, Jones TH. Testosterone replacement therapy improves insulin resistance, glycaemic control, visceral adiposity and hypercholesterolaemia in hypogonadal men with type 2 diabetes. Eur J Endocrinol 2006;154:899-906. DOI: 10.1530/eje.1.02166; PMID: 16728551

22. Simon D, Charles MA, Lahlou N, et al. Androgen therapy improves insulin sensitivity and decreases leptin level in healthy adult men with low plasma total testosterone: a 3-month randomized placebo-controlled trial. Diabetes Care 2001;24:2149-51. DOI: 10.2337/diacare.24.12.2149; PMID: 11723098 .

23. Hackett G, Cole N, Bhartia M, et al. Testosterone replacement therapy improves metabolic parameters in hypogonadal men with type 2 diabetes but not in men with coexisting depression: the BLAST study. I sex Med 2014;11:840-56. depression: the BLAST study. J sex Med 2014

24. Muller M, van den Beld AW, Bots ML, et al. Endogenous sex hormones and progression of carotid atherosclerosis in elderly men. Circulation 2004;109:2074-9. DOI: 10.1161/01. CIR.0000125854.51637.06; PMID: 15096452

25. Basaria S, Harman SM, Travison TG, et al. Effects of testosterone administration for 3 years on subclinical atherosclerosis progression in older men with low or low-normal testosterone levels: A randomized clinical trial. JAMA 2015;314:570-81. DOI: 10.1001/jama.2015.8881; PMID: 26262795

26. Snyder PJ, Ellenberg SS, Cunningham GR, et al. The Testosterone Trials: Seven coordinated trials of testosterone treatment in elderly men. Clin Trials 2014;11:362-75. DO 10.1177/1740774514524032; PMID: 24686158.

27. Budoff MJ, Ellenberg SS, Lewis CE, et al. Testosterone treatment and coronary artery plaque volume in older men with low testosterone. JAMA 2017;317:708-16. DOI: 10.1001/ jama.2016.21043; PMID: 28241355.

28. Yue P, Chatterjee K, Beale C, et al. Testosterone relaxes rabbit coronary arteries and aorta. Circulation 1995;91: 1154-60. DOI: 10.1161/01.CIR.91.4.1154; PMID: 7850954.

29. Chou TM, Sudhir K, Hutchison SJ, et al. Testosterone induces dilation of canine coronary conductance and resistance arteries in vivo. Circulation 1996;94:2614-9. DOI: 10.1161/01. CIR.94.10.2614; PMID: 8921808.

30. Rowell KO, Hall J, Pugh PJ, et al. Testosterone acts as an efficacious vasodilator in isolated human pulmonary arteries and veins: evidence for a biphasic effect at physiological and supra-physiological concentrations. J Endocrinol Invest 2009;32:718-23. DOI: 10.1007/BF03346526; PMID: 19535892.

31. Webb CM, MCNeill JG, Hayward CS, et al. Effects of testosterone on coronary vasomotor regulation in men with coronary heart disease. Circulation 1999;100:1690-6. DOI: 10.1161/01.CIR.100.16.1690; PMID: 10525487.

32. Webb CM, Elkington AG, Kraidly MM, et al. Effects of oral testosterone treatment on myocardial perfusion and vascular 
function in men with low plasma testosterone and coronary heart disease. Am / Cardiol 2008;101:618-24. DOI: 10.1016/ j.amjcard.2007.09.114; PMID: 18308009.

33. Ong PJ, Patrizi G, Chong WC, et al. Testosterone enhances flow-mediated brachial artery reactivity in men with coronary artery disease. Am J Cardiol 2000;85:269-72. DOI: 10.1016/ S0002-9149(99)00630-X

34. Hougaku H, Fleg JL, Najjar SS, et al. Relationship between androgenic hormones and arterial stiffness, based on longitudinal hormone measurements. Am J Physiol Endocrinol Metab 2006;290:E234-42. DOI: 10.1152/ajpendo.00059.2005; Metab 2006;290.

35. Dockery F, Bulpitt CJ, Donaldson M, et al. The relationship between androgens and arterial stiffness in older men. J Am Geriatr Soc 2003:51:1627-32. DOI: 10.1046/j.15325415.2003.51515.x; PMID: 14687394.

36. Yaron M, Greenman Y, Rosenfeld JB, et al. Effect of testosterone replacement therapy on arterial stiffness in older hypogonadal men. Eur J Endocrinol 2009:160:839-46. DOI: 10.1530/EJE-09-0052; PMID: 19174534.

37. English KM, Steeds RP, Jones TH, et al. Low-dose transderma testosterone therapy improves angina threshold in men with chronic stable angina: A randomized, double-blind, placebocontrolled study. Circulation 2000;102:1906-11. DOI: 10.1161/ 01.CIR. 102.16.1906; PMID: 11034937

38. Malkin CJ, Pugh PJ, Morris PD, et al. Testosterone replacement in hypogonadal men with angina improves ischaemic threshold and quality of life. Heart 2004;90:871-6. DOI: 10.1136/hrt.2003.021121; PMID: 15253956

39. Webb CM, Adamson DL, de ZD, Collins P. Effect of acute testosterone on myocardial ischemia in men with coronary
artery disease. Am J Cardiol 1999:83:437-9, A9. PMID: 10072236

40. Mathur A, Malkin C, Saeed B, et al. Long-term benefits of testosterone replacement therapy on angina threshold and atheroma in men. Eur J Endocrinol 2009;161:443-9. DOI: 10.1530/ EJE-09-0092; PMID: 19542238

41. Jankowska EA, Filippatos G, Ponikowska B, et al. Reduction in circulating testosterone relates to exercise capacity in men with chronic heart failure. I Card Fail 2009;15:442-50. DOI: 10.1016/j.cardfail.2008.12.011: PMID: 19477405.

42. von Haehling S, Ebner N, Dos Santos MR, et al. Muscle wasting and cachexia in heart failure: mechanisms and therapies. Nat Rev Cardiol 2017:14:323-41. DOl: 10.1038/ therapies. Nat Rev Cardiol 2017;14.323-4

43. Anker SD, Chua TP, Ponikowski P, et al. Hormonal changes and catabolic/anabolic imbalance in chronic heart failure and their importance for cardiac cachexia. Circulation 1997; 96:526-34. DOI: 10.1161/01.CIR.96.2.526; PMID: 9244221

44. Pugh PJ, Jones TH, Channer KS. Acute haemodynamic effects of testosterone in men with chronic heart failure. Eur Heart J 2003;24:909-15. DOI: 10.1016/S0195-668X(03)00083-6; PMID: 12714022.
45. Malkin CJ, Pugh PJ, West JN et al. Testosterone therapy in men with moderate severity heart failure: a double-blind randomized placebo controlled trial. Eur Heart J 2006;27:57-64 DOI: 10.1093/eurheartj/ehi443; PMID: 16093267

46. Caminiti $\mathrm{G}$, Volterrani $\mathrm{M}$, Iellamo $\mathrm{F}$, et al. Effect of longacting testosterone treatment on functional exercise capacity, skeletal muscle performance, insulin resistance and baroreflex sensitivity in elderly patients with chronic heart failure a double-blind, placebo-controlled, randomized study. J Am Coll Cardiol 2009;54:919-27. DOl: 10.1016/i. jacc. 2009.04.078: PMID: 19712802

47. Pugh PJ, Jones RD, West JN, et al. Testosterone treatment for men with chronic heart failure. Heart 2004;90:446-7. DOI: 10.1136/hrt.2003.014639; PMID: 15020527

48. Iellamo F, Volterrani M, Caminiti G, et al. Testosterone therapy in women with chronic heart failure: a pilot doubleblind, randomized, placebo-controlled study. J Am Coll Cardiol 2010;56:1310-6. DOI: 10.1016/j.jacc.2010.03.090; PMID: 20888520.

49. Toma M, MCAlister FA, Coglianese EE, et al. Testosterone supplementation in heart failure: a meta-analysis. Circ Heart Fal 2012;5:315-21. DOI: 10.1161/CIRCHEARTFAILURE.111.965632; PMID: 22511747

50. Barrett-Connor E, Khaw KT. Endogenous sex hormones and cardiovascular disease in men. A prospective populationbased study. Circulation 1988;78:539-45. DOI: 10.1161/01. CIR.78.3.539; PMID: 3409497

51. Vikan T, Schirmer H, Njolstad I, Svartberg J. Endogenous sex hormones and the prospective association with cardiovascular disease and mortality in men: the Tromso Study Eur J Endocrinol 2009:161:435-42. DO1: 10.1530/EJE-090284: PMID: 19542243.

52. Yeap BB, Hyde Z, Almeida OP, et al. Lower testosterone levels predict incident stroke and transient ischemic attack in older men. J Clin Endocrinol Metab 2009;94:2353-9. DOI: 10.1210/ jc.2008-2416; PMID: 19351733

53. Maggi $\mathrm{M}, \mathrm{Wu} \mathrm{FC}$, Jones $\mathrm{TH}$, et al. Testosterone treatment is not associated with increased risk of adverse cardiovascular events: results from the Registry of Hypogonadism in Men (RHYME). Int J Clin Pract 2016;70:843-52. DOI: 10.1111/ ijcp.12876; PMID: 27774779.

54. Ohlsson C, Barrett-Connor E, Bhasin S, et al. High serum testosterone is associated with reduced risk of cardiovascular events in elderly men. The MrOS (Osteoporotic Fractures in Men) study in Sweden. J Am Coll Cardiol 2011;58:1674-81. DOI 10.1016/j.jacc.2011.07.019; PMID: 21982312

55. Finkle WD, Greenland S, Ridgeway GK, et al. Increased risk of non-fatal myocardial infarction following testosterone therapy prescription in men. PLOS One 2014;9:e85805. DOI: 10.1371/ journal.pone.0085805; PMID: 24489673.

56. Vigen $\mathrm{R}, \mathrm{O}^{\prime} \mathrm{Donnell} \mathrm{Cl}$, Baron $\mathrm{AE}$, et al. Association of testosterone therapy with mortality, myocardial infarction, and stroke in men with low testosterone levels. JAMA 2013 310:1829-36. DOl: 10.1001/jama 2013 280386: PMID: 24193080.

57. Morgentaler A, Kacker R. Andrology: Testosterone and cardiovascular risk-deciphering the statistics. Nat Rev Urol 2014;11:131-2. DOI: 10.1038/nrurol.2014.24; PMID: 24535586.

58. Wallis CJ, Lo K, Lee Y, et al. Survival and cardiovascular events in men treated with testosterone replacement therapy: an intention-to-treat observational cohort study Lancet Diabetes Endocrinol 2016;4:498-506. DOI: 10.1016/S2213-8587(16)00112-1.

59. Cheetham TC, An J, Jacobsen SJ, et al. Association of Testosterone Replacement With Cardiovascular Outcomes Among Men With Androgen Deficiency. JAMA Intern Med 2017;177:491-9. DOI: 10.1001/jamainternmed.2016.9546; PMID: 28241244

60. Sharma R, Oni OA, Gupta K, et al. Normalization of testosterone level is associated with reduced incidence of myocardial infarction and mortality in men. Eur Heart J 2015:36:2706-15. DOI: 10.1093/eurhearti/ehv346; PMID: 26248567.

61. Basaria S, Coviello AD, Travison TG, et al. Adverse events associated with testosterone administration. N Engl I Med 2010;363:109-22. DOI: 10.1056/NEJMoa1000485; PMID: 20592293.

62. Snyder PJ, Ellenberg SS, Farrar JT; Testosterone Trials Investigators. Testosterone Treatment in Older Men. N Eng J Med 2016;375:90. DOI: 10.1056/NEJMoa1506119; PMID: 27406354

63. Onasanya $\mathrm{O}$, lyer $\mathrm{G}$, Lucas $\mathrm{E}$, et al. Association between exogenous testosterone and cardiovascular events: an overview of systematic reviews. Lancet Diabetes Endocrinol 2016:4:943-6. DOl: 10.1016/S2213-8587(16)30215-7; PMID: 2016;4:943-6.

64. Rhoden EL, Morgentaler A. Risks of testosterone-replacement therapy and recommendations for monitoring. $N$ Eng/ J Med 2004;350:482-92. DOI: 10.1056/NEJMra022251; PMID: 14749457.

65. Morales A. Androgen replacement therapy and prostate safety. Eur Urol 2002;41:113-20. DOI: 10.1016/S03022838(01)00039-2; PMID: 12074396

66. Klotz L. Testosterone therapy and prostate cancer-safety concerns are well founded. Nat Rev Urol 2015;12:48-54. DOl: 10.1038/nrurol 2014.338: PMID. 25563848.

67. Bhasin $\mathrm{S}$, Cunningham GR, Hayes FJ, et al. Testosterone therapy in men with androgen deficiency syndromes: an Endocrine Society clinical practice guideline. J Clin Endocrinol Metab 2010;95:2536-59. DOI: 10.1210/jcem.95.6.9999; PMID: 20525905.

68. Dimopoulou C, Ceausu I, Depypere H, et al. EMAS position statement: Testosterone replacement therapy
in the aging male. Maturitas 2016;84:94-9. DOI: 10.1016/ j.maturitas.2015.11.003; PMID: 26614257. 